ARTICLE

\title{
Effect of the supergravity on the formation and cycle life of non-aqueous lithium metal batteries
}

\author{
Yuliang Gao ${ }^{1}$, Fahong Qiao ${ }^{1}$, Jingyuan You' ${ }^{1}$ Zengying Ren ${ }^{1}$, Nan $\mathrm{Li}^{1}$, Kun Zhang ${ }^{1}$, Chao Shen ${ }^{1}$, Ting $\operatorname{Jin}^{1} \&$
} Keyu Xie (1) $1,2 \times$

Extra-terrestrial explorations require electrochemical energy storage devices able to operate in gravity conditions different from those of planet earth. In this context, lithium (Li)-based batteries have not been fully investigated, especially cell formation and cycling performances under supergravity (i.e., gravity $>9.8 \mathrm{~m} \mathrm{~s}^{-2}$ ) conditions. To shed some light on these aspects, here, we investigate the behavior of non-aqueous Li metal cells under supergravity conditions. The physicochemical and electrochemical characterizations reveal that, distinctly from earth gravity conditions, smooth and dense Li metal depositions are obtained under supergravity during Li metal deposition on a Cu substrate. Moreover, supergravity allows the formation of an inorganic-rich solid electrolyte interphase (SEI) due to the strong interactions between $\mathrm{Li}^{+}$and salt anions, which promote significant decomposition of the anions on the negative electrode surface. Tests in full $\mathrm{Li}$ metal pouch cell configuration (using $\mathrm{LiNi}_{0.8^{-}}$ $\mathrm{Co}_{0.1} \mathrm{Mn}_{0.1} \mathrm{O}_{2}$-based positive electrode and LiFSI-based electrolyte solution) also demonstrate the favorable effect of the supergravity in terms of deposition morphology and SEI composition and ability to carry out 200 cycles at $2 \mathrm{C}\left(400 \mathrm{~mA} \mathrm{~g}^{-1}\right)$ rate with a capacity retention of $96 \%$.

\footnotetext{
${ }^{1}$ State Key Laboratory of Solidification Processing, Center for Nano Energy Materials, School of Materials Science and Engineering, Northwestern Polytechnical University and Shaanxi Joint Laboratory of Graphene (NPU), Xi'an 710072, People's Republic of China. ${ }^{2}$ Research \& Development Institute of Northwestern Polytechnical University in Shenzhen, Northwestern Polytechnical University, Shenzhen 518057, People's Republic of China.

凶email: kyxie@nwpu.edu.cn
} 


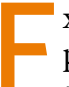
xplaining the formation and evolution of the universe and planets, exploring extraterrestrial life, and establishing permanent human settlements in space are significant reasons why researchers from all over the world are obsessed with outer space ${ }^{1,2}$. Complicated service conditions cause various devices (rockets, satellites, and detectors) to be in short-term or longterm special environments, including microgravity and supergravity (Fig. 1a). In general, supergravity $\left(G>9.8 \mathrm{~m} \mathrm{~s}^{-2}\right)$ is the force of matter greater than that under normal gravity acceleration, while microgravity $\left(G<9.8 \mathrm{~m} \mathrm{~s}^{-2}\right)$ is the opposite ${ }^{3,4}$. As a vital module of space equipment, current aerospace qualified battery technologies must not only adapt to the harsh environment, but also meet the mass and volume requirements of the target mission ${ }^{5,6}$.

Compared with advanced Li-ion batteries with the same energy density, Li metal batteries are more compact due to their lower mass, volume, and capacity ${ }^{7,8}$. Such high specific energy property can not only reduce the detection cost of the transmitter, but also reserve more mass and space for other necessary materials and equipment, and at the same time provide a longer cruising range for specific equipment. Therefore, $\mathrm{Li}$ metal batteries have tremendous potential in future space exploration. However, the current research and evaluation are limited to normal gravity ${ }^{9-15}$. A fundamental understanding of how the $\mathrm{Li}$ metal batteries behave over a wide range of gravity, like over 1G, is ambiguous.

Supergravity occurs in special planets (e.g., Jupiter, Saturn, and Neptune) and detection carriers that accelerate ascent or decelerate. Jupiter, one of the eight planets in the solar system, is part of NASA's space exploration program, which began with the launch of the first dedicated Galileo probe in 1989 and again in 2011 with the launch of the Juno probe ${ }^{16,17}$. The China Space Administration is also expected to start a Jupiter exploration program in $2030^{18}$. In addition, NASA is planning to launch a probe to explore Saturn in 2026 and to start the Neptune exploration program within the next 20 years ${ }^{19}$. Obviously, understanding the working mechanism of materials and equipment under supergravity is of great significance to the smooth development of the planetary exploration program. Supergravity is commonly obtained on the earth by circulating centrifugal force. Under supergravity, centrifugal acceleration approaches to 1000 times gravity acceleration of $9.81 \mathrm{~m} \mathrm{~s}^{-2}$, diphase dynamic factor is substantially raised, and relative speeds of different constitutes in solution are markedly increased ${ }^{20}$. Therefore, supergravity plays an active role in enhancing mass transfer process, momentum transfer, and energy transmission, gaining great attention in material separation, rectification, especially electrochemical deposition $^{21,22}$. Specifically, supergravity was employed in the electropolymerization of the conductive polymers to obtain higher stability and conductivity ${ }^{23}$. Unlike normal gravity, nickelmetal electrodeposition exhibits a distinctive deposition behavior and morphology under supergravity ${ }^{24}$. Furthermore, amorphous tungsten-nickel alloy films exhibited good catalytic activity for hydrogen evolution reaction under supergravity ${ }^{25}$. Essentially, the working mechanism of the Li metal electrode is a classic electroplating and stripping process, meaning that supergravity may impact the fundamental electrochemical behavior of Li metal.

To validate this conjecture, herein, we introduced supergravity during the operation of $\mathrm{Li}$ metal batteries and revealed the

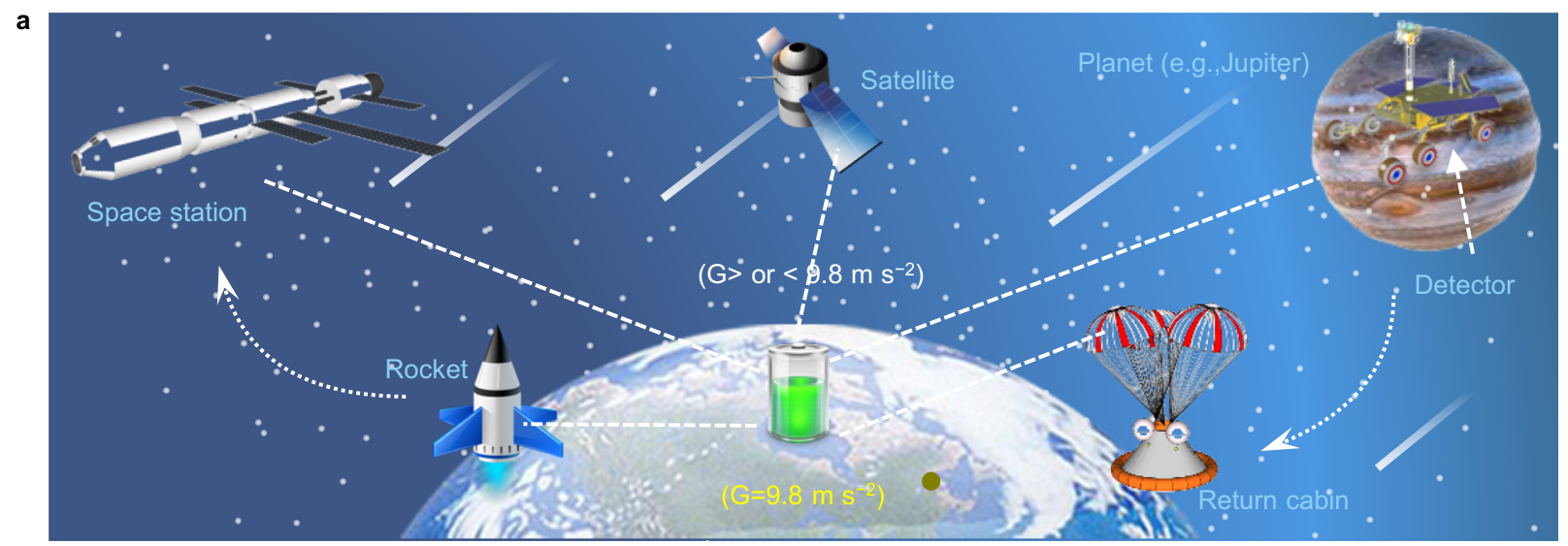

b

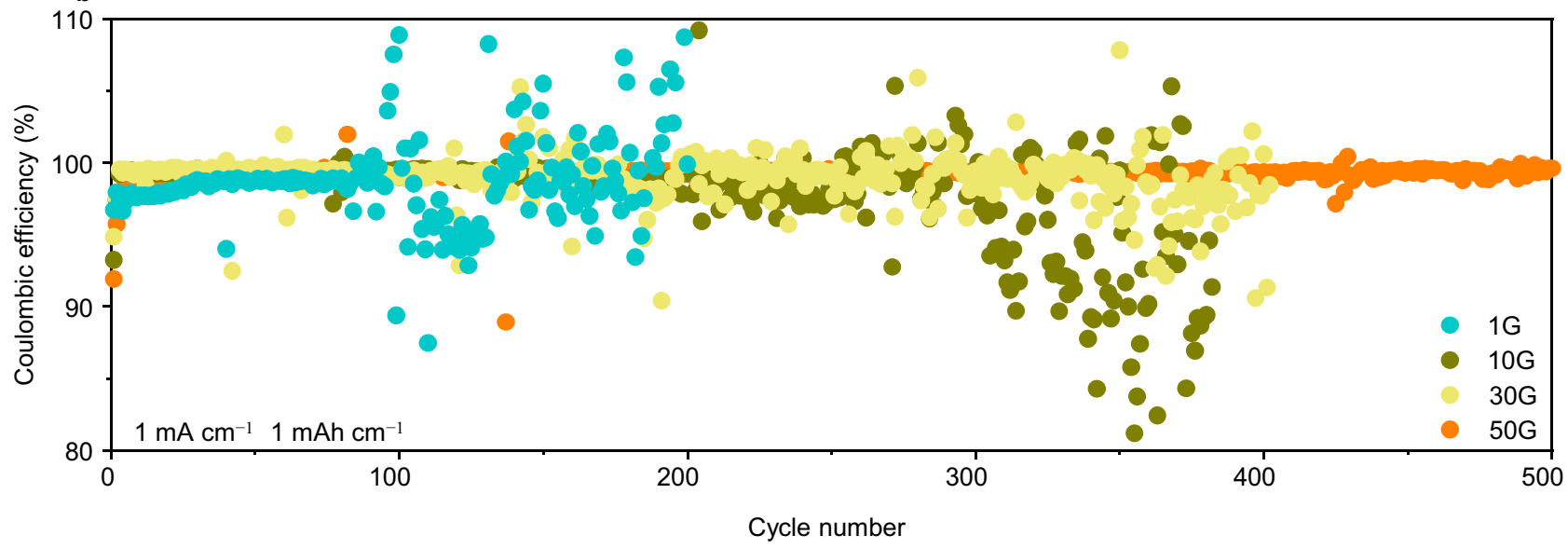

Fig. 1 The application background of Li metal batteries and its electrochemical performance under supergravity. a Potential applications of Li metal batteries in space exploration. $\mathbf{b}$ Long-term cycling of Li ||$C$ cells with a fixed capacity of $1 \mathrm{~mA} \mathrm{~h} \mathrm{~cm}{ }^{-2}$ at a current density of $1 \mathrm{~mA} c \mathrm{~cm}^{-2}$ under different gravity conditions. 
electrochemical behavior of $\mathrm{Li}$ metal in detail. Unlike normal gravity, Li metal electrodes exhibit some new electrode behaviors under supergravity. Specifically, morphological observations indicate that supergravity refines Li particles and presents a dense dendrite-free morphology. Meanwhile, the results reveal that supergravity changes the solvation structure and binding energy of the electrolyte, and enhances the interaction between $\mathrm{Li}^{+}$and anions, which forms a favorable anion-derived inorganic-rich solid electrolyte interphase (SEI). As a result, the $\mathrm{Li}|| \mathrm{LiNi}_{0.8^{-}}$ $\mathrm{Co}_{0.1} \mathrm{Mn}_{0.1} \mathrm{O}_{2}$ (NCM811) pouch cell (2.5 $\left.\mathrm{Ah}, 325 \mathrm{Wh} \mathrm{kg}^{-1}\right)$ shows a stable cycling life of 200 cycles at $2 \mathrm{C}\left(400 \mathrm{~mA} \mathrm{~g}^{-1}\right)$ rate. The performance proves the feasibility of Li metal batteries in supergravity applications and also provides meaningful guidance for research under microgravity.

\section{Results}

Performance evaluation under supergravity. To explore the influence of supergravity on the electrochemical performance of $\mathrm{Li}$ metal batteries in future space exploration, $\mathrm{Li}|| \mathrm{Cu}$ cells were first employed for evaluation. Supergravity was supplied by rotating centrifugal force, which is a typical practice at present $^{26,27}$, and the coefficients (1G, 1G,30G, and 50G) and direction (parallel and perpendicular to the electric field) of supergravity are adjusted by rotational speed and the fixed angle of the battery (Supplementary Fig. 1a, b and Supplementary Video). Note that $G$ value equal to 1 indicates normal gravity condition, abbreviated as $1 \mathrm{G}$, and the rest are analogous. Fig. $1 \mathrm{~b}$ compares the Coulombic efficiency (CE) of $\mathrm{Li}|| \mathrm{Cu}$ cells at a current density of $1 \mathrm{~mA} \mathrm{~cm}-2$ with a capacity of $1 \mathrm{~mA} \mathrm{~h} \mathrm{~cm}^{-2}$ under different gravity coefficients. For the cells cycled at $1 \mathrm{G}$, the $\mathrm{CE}$ at the early stage can rebound to $99.1 \%$, but fluctuates after 84 cycles, which could be attributed to the repeated growth/dissolution of Li metal. Increasing the gravity coefficient to $10 \mathrm{G}$, the CE fluctuates gradually after 250 cycles, while the CE remains stable for the cells cycled at 30G. Further raised to 50G, the cell exhibits a fairly high and stable CE of $99.3 \%$ for 500 cycles, showing good cycle stability and Li utilization. The higher and stable $\mathrm{CE}$ of the $\mathrm{Li}$ metal electrode indicates the uniform deposition of Li under supergravity, and the formation of a stable SEI that can suppress parasitic reactions during the repeated plating/stripping. When applying a much higher current density $\left(3 \mathrm{~mA} \mathrm{~cm}^{-2}\right.$, Supplementary Fig. 2), such an enhanced effect is still noticeable. The rapid $\mathrm{CE}$ decay and cell failure can be ascribed to the formation of dead $\mathrm{Li}$ (i.e., Li metal regions which are electronically disconnected from the current collector) and unfavorable Li metal depositions (e.g., dendrites).

$\mathrm{Li}|| \mathrm{Li}$ symmetrical cells were further applied to evaluate the performance of $\mathrm{Li}$ metal electrodes under supergravity. At a current density of $1 \mathrm{~mA} \mathrm{~cm}^{-2}$ (Supplementary Fig. 3a), for the cell cycled at $1 \mathrm{G}$, the plating/stripping overpotential was initially maintained at $140 \mathrm{mV}$ and stepped up gradually to $362 \mathrm{mV}$ after $90 \mathrm{~h}$. Subsequently, a sudden drop in overpotential was detected, followed by appreciable voltage fluctuation, which could be explained as the internal soft shorting of the cell owing to the $\mathrm{Li}$ dendrites formation ${ }^{28}$. When the gravity coefficient is $10 \mathrm{G}$, the lifespan $(210 \mathrm{~h})$ is longer than that of the control group $(90 \mathrm{~h})$, but poorer than the cell cycled at $30 \mathrm{G}(470 \mathrm{~h})$. Further increases to $50 \mathrm{G}$, a lifespan of more than $600 \mathrm{~h}$ with a smallest polarization of $30 \mathrm{mV}$ was achieved. At a high current density of $3 \mathrm{~mA} \mathrm{~cm}-2$ (Supplementary Fig. 3b), the cell is cycled for $50 \mathrm{~h}$ at $1 \mathrm{G}$ before failure, and presents a large polarization voltage during the whole operation process. By contrast, the cycle life of the cells with gravity coefficients of $10 \mathrm{G}, 30 \mathrm{G}$, and $50 \mathrm{G}$ are $1.8,4.1$, and 6.2 times that of $1 \mathrm{G}$, respectively. The performance shows $\mathrm{Li}$ plating with a decreased diffusion barrier and realizes uniform deposition. Both $\mathrm{Li}|| \mathrm{Cu}$ cells and symmetrical $\mathrm{Li}|| \mathrm{Li}$ cells also show good performance under the perpendicular supergravity direction, further verifying the positive impact of supergravity on the electrochemical performance of Li metal batteries (Supplementary Fig. 4).

Electrodeposition morphology of Li metal under supergravity. To reveal the potential mechanism behind the improvement of electrochemical performance, scanning electron microscopy (SEM) was utilized to provide detailed morphology under different supergravity scenarios. Similar to cells with ester-based electrolytes $^{29,30}$, dendritic formations are distributed on the $\mathrm{Cu}$ surface after using $1.0 \mathrm{M}$ lithium hexafluorophosphate $\left(\mathrm{LiPF}_{6}\right)$-ethylene carbonate/diethyl carbonate/ethyl methyl carbonate (EC/DEC/EMC) electrolyte to plate $0.5 \mathrm{~mA} \mathrm{~h} \mathrm{~cm}^{-2}$ at $1 \mathrm{G}$ (Fig. 2a and Supplementary Fig. 5a). On this basis, continue to deposit to $1 \mathrm{~mA} \mathrm{~h} \mathrm{~cm}^{-2}$ at $50 \mathrm{G}$ (Fig. $2 \mathrm{~b}$ and Supplementary Fig. 5b), and the upper layer of the deposition morphology presents a favorable nodular structure while the lower layer has a clear dendritic morphology, which implies that the supergravity inhibits the subsequent growth of Li dendrites. When $0.5 \mathrm{~mA} \mathrm{~h}$ $\mathrm{cm}^{-2}$ is first deposited on the $\mathrm{Cu}$ foil at $50 \mathrm{G}$, the tiny nodular morphology appears (Fig. $2 \mathrm{c}$ and Supplementary Fig. 5c), indicating the positive effect of supergravity on the inhibition of $\mathrm{Li}$ dendrites. Then continues to deposit to $1 \mathrm{~mA} \mathrm{~h} \mathrm{~cm}^{-2}$ at $1 \mathrm{G}$ (Fig. 2d and Supplementary Fig. 5d), the dendrites reappear but better than the deposition morphology under normal gravity only. Unlike the long-lasting effect provided by customized $\mathrm{SEI}^{31,32}$, although a favorable SEI forms in supergravity, the rougher electrode accelerates the irregular growth of Li metal at the protrusion (distorted electric field lines), resulting in SEI rupture that cannot regulate subsequent growth. Moreover, the slow mass transfer after the withdrawal of supergravity is not conducive to the uniform deposition of Li metal. To clarify the influence of supergravity on the entire nucleation and growth process of Li dendrites, different deposition capacities $(0.2,1$, and $4 \mathrm{~mA} \mathrm{~h} \mathrm{~cm}^{-2}$ ) at a current density of $1 \mathrm{~mA} \mathrm{~cm}^{-2}$ were selected. For a small amount of deposition $\left(0.2 \mathrm{~mA} \mathrm{~h} \mathrm{~cm}^{-2}\right.$, Supplementary Fig. 6), Li metal exhibits a sparse, short fibrous structure at $1 \mathrm{G}$, which is in agreement with the reported result ${ }^{33}$. However, the initial deposition morphology of Li metal turned sharply under supergravity, the unfavorable short fibrous morphology disappeared, and evolved into a more favorable morphology. Specifically, with the increase of gravity coefficient, the initial fibrous structure gradually evolved into a short rod-shaped structure, and oval-shaped structure. As shown in Fig. 2e, due to the tip effect of $\mathrm{Li}$ dendrites, at $1 \mathrm{G}$, the deposition capacity continues to $1 \mathrm{mAh} \mathrm{cm}^{-2}$, and the surface of the Li metal electrode showed messy Li dendrites with a length of several micrometers. In contrast, the growth of Li dendrites was eliminated under supergravity, and the larger the gravity coefficient, the denser and smoother the deposition morphology (Fig. $2 \mathrm{f}-\mathrm{h}$ ). As shown in inserted 3D topography from atomic force microscopy (AFM), the deposition morphology of Li metal varies from 0 to $200 \mathrm{~nm}$ and there are numerous gullies at $1 \mathrm{G}$, indicating the formation of Li dendrites, which provides convenient conditions for the parasitic reaction between Li metal and the electrolyte, and ultimately causes the rapid failure of the cell. As a comparison, under supergravity, the electrode surface becomes smoother and more uniform, and the maximum height is reduced to 120,80 , and $40 \mathrm{~nm}$ at $10 \mathrm{G}, 30 \mathrm{G}$, and $50 \mathrm{G}$ respectively. The cross-sectional SEM images further show that supergravity reduces the growth of porous Li to obtain a uniform deposited layer (Supplementary

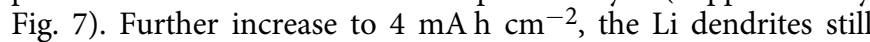
exist at $1 \mathrm{G}$, while the dense and smooth deposition morphology 

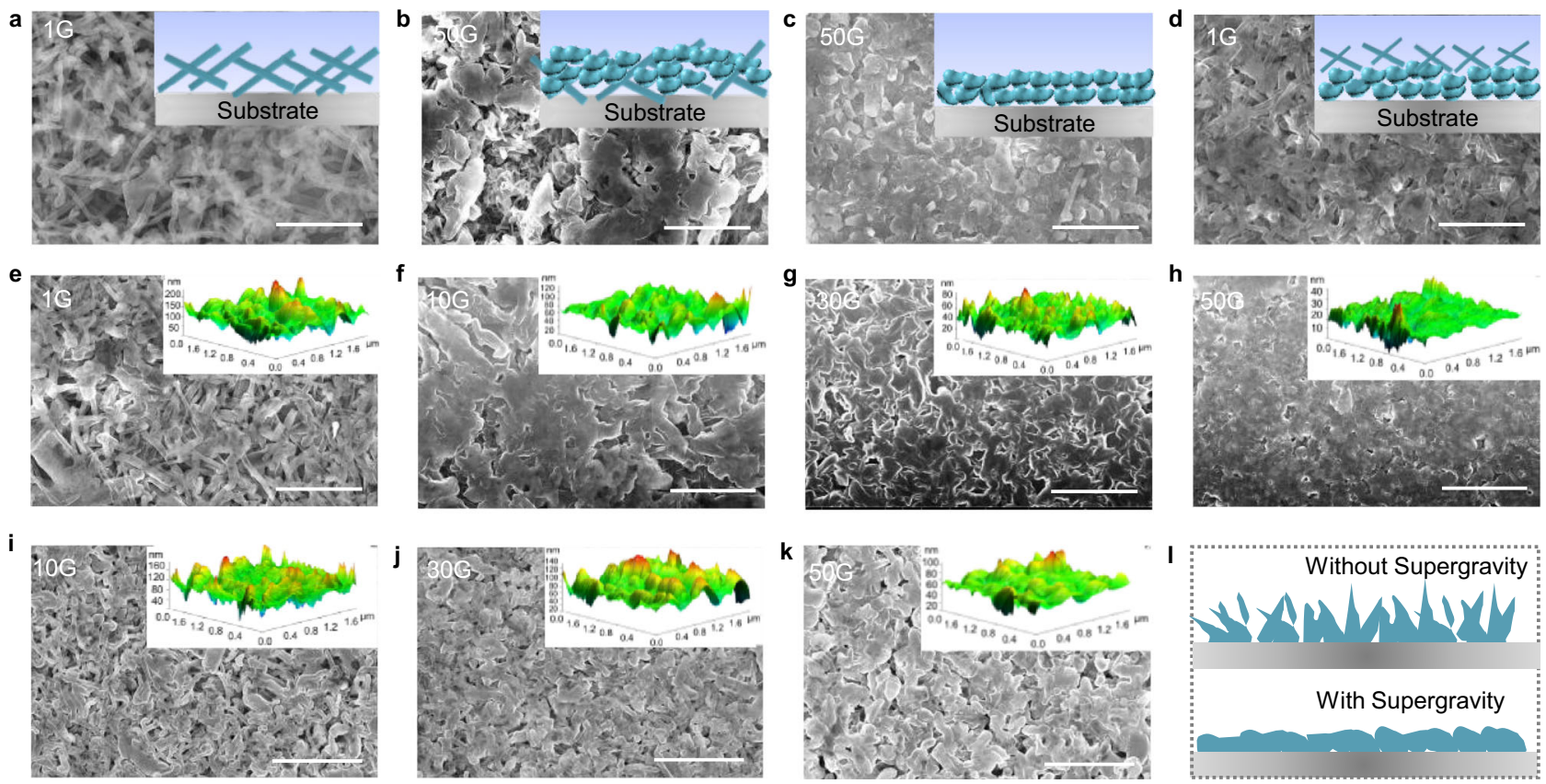

Fig. 2 Morphology characterization of Li metal under different gravity conditions. SEM images of deposited Li on Cu after plating $0.5 \mathrm{~mA} h \mathrm{~cm}{ }^{-2}$ at a $1 \mathrm{G}$

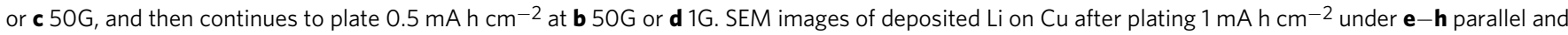
$\mathbf{i}-\mathbf{k}$ perpendicular supergravity directions. I Schematic illustration of electrodeposition morphology under different gravity conditions. Note that the images inserted in the upper right corner are used to illustrate the corresponding morphological evolution, including $\mathbf{a}-\mathbf{d}$ sketches drawn and $\mathbf{e}-\mathbf{k} 3 \mathrm{D}$ topography from AFM. Scale bars are $5 \mu \mathrm{m}$ in $(\mathbf{a}-\mathbf{k})$.

can be maintained under supergravity (Supplementary Fig. 8). Under perpendicular supergravity direction, Li metal also shows favorable deposition morphology (Fig. 2i-k and Supplementary Fig. 9), even at a high deposition capacity (Supplementary Fig. 10), but the morphology is slightly worse to parallel supergravity direction. It can be seen that supergravity can effectively inhibit the dendrites growth and endow the Li metal electrode a uniform and dense morphology (Fig. 21).

Intrinsic mechanism of morphology evolution under supergravity. Regarding the refining behavior of Li particles under supergravity and the difference in deposition morphology under different supergravity conditions, a detailed explanation can be given from the perspective of nucleation and growth. For the nucleation stage, due to the lithiophobic of $\mathrm{Cu}$, the nucleation energy barrier of Li metal is high under normal gravity condition, resulting in a larger nucleus size and a smaller nucleation density, which also provides a prerequisite for the subsequent sparse dendritic morphology (Fig. 3a). When supergravity is introduced in the electrodeposition process, the nucleation energy barrier is reduced, promoting the nucleation of Li metal. To illustrate this phenomenon, we conducted a detailed theoretical analysis from the perspective of electrocrystallization. Under normal gravity, as shown in Eq. (1), the free energy of the system $(\Delta G)$ is the sum of bulk-free energy and surface free energy. After applying supergravity, the free energy induced by supergravity is newly added, and the $\Delta G$ is shown in Eq. $(2)^{34,35}$ :

$$
\begin{gathered}
\triangle G=-\frac{4}{3} \pi r^{3} \triangle G_{V}+4 \pi r^{2} \sigma_{l s} \\
\triangle G=-\frac{4}{3} \pi r^{3} \triangle G_{V}-\frac{4}{3} \pi r^{3} k \varepsilon \mathbf{F}+4 \pi r^{2} \sigma_{l s}
\end{gathered}
$$

Where $r$ is the radius of the crystal nucleus, $\triangle G_{V}$ is the free energy change per volume, $k$ is the conversion coefficient, $\varepsilon$ is the bulk shrinkage, $\mathbf{F}$ is supergravity, $\sigma_{l s}$ is the surface energy of the Li-electrolyte interface.

To clearly explain the change of free energy under supergravity, a microvolume element $(\mathrm{d} R)^{2}$ is taken on the surface of the electrode, and its mass center is on the $R-\mathrm{d} R / 2$ plane. Since the value of $\mathrm{d} R$ is extremely small, it can be dealt with that $R-\mathrm{d} R /$ $2=R$. The supergravity $(\mathbf{F})$ and radial pressure (p) generated when the micro-volume element rotates are as follows.

$$
\begin{gathered}
\mathrm{d} \mathbf{F}=m \omega^{2} R=\rho(\mathrm{d} R)^{3} \omega^{2} R \\
\mathrm{~d} \mathbf{p}=\mathrm{d} \mathbf{F} /(\mathrm{d} R)^{2}
\end{gathered}
$$

Where $m$ represents the unit volume mass, $\rho$ represents the liquid density. Through the integrated calculation of formulas (1)-(4), $\mathbf{p}$ and $\triangle G$ can be obtained.

$$
\begin{gathered}
\mathbf{p}=\rho \omega^{2}\left(R^{2}-R_{0}^{2}\right) / 2 \\
\triangle G=-\frac{4}{3} \pi r^{3} \triangle G_{V}-\frac{2}{3} \pi r^{3} k \varepsilon \boldsymbol{F} \omega^{2}\left(R^{2}-R_{0}^{2}\right)+4 \pi r^{2} \sigma_{l s}
\end{gathered}
$$

Let $\mathrm{d} \Delta G / \mathrm{d} r=0$, the critical nucleation radius $r^{*}$ can be obtained.

$$
r^{*}=2 \sigma_{l s} /\left[\frac{k \varepsilon \rho \omega^{2}\left(R^{2}-R_{0}^{2}\right)}{2}+\Delta G_{V}\right]
$$

Substituting formula (7) into (6), the critical nucleation work $\triangle G^{*}$ under supergravity is as follows.

$$
\Delta G^{*}=16 \pi \sigma_{l s}^{3} /\left\{3\left[\Delta G_{V}+\frac{k \varepsilon \rho \omega^{2}\left(R^{2}-R_{0}^{2}\right)}{2}\right]^{2}\right\}
$$

To simplify the calculation, several hypotheses are set: (i) Gibbs free energy formula is obtained under the condition of spontaneous nucleation; (ii) bulk shrinkage $\varepsilon$, surface tension $\sigma_{l s}$ and $\triangle G_{V}$ are independent of supergravity; (iii) $R_{0}=0$. 
a

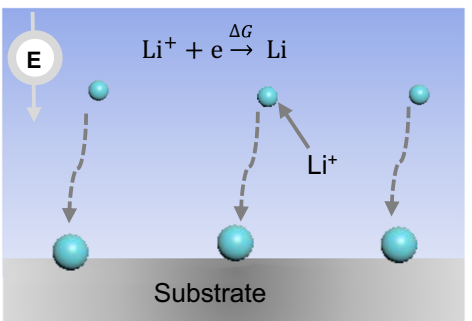

b

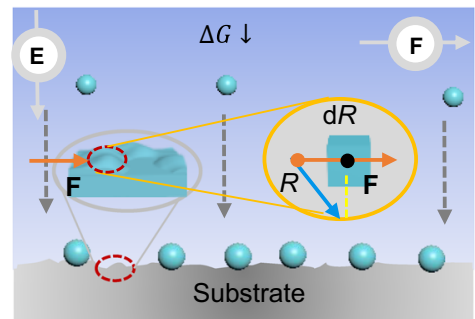

c

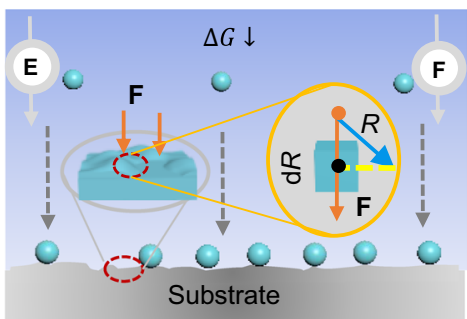


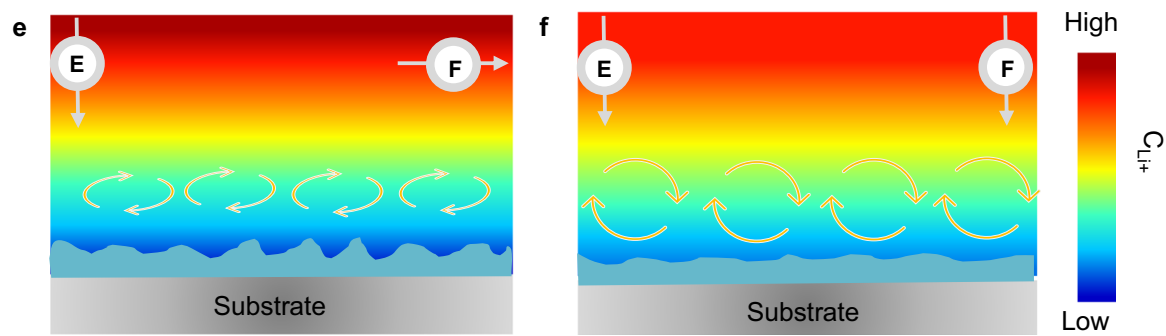

Fig. 3 Morphological evolution of the Li metal depositions. Schematic illustrations of the nucleation and growth of Li metal under a, $\mathbf{d} 1 \mathrm{G}$ gravity, b, e perpendicular and $\mathbf{c}, \mathbf{f}$ parallel supergravity conditions. Note that "E" represents the applied electric field, "F" represents the applied supergravity, and the color change represents the difference in ion concentration in the solution.

Therefore, $\Delta G^{*}$ can be simplified to the following formula.

$$
\triangle G^{*}=16 \pi \sigma_{l s}^{3} /\left[3\left(\triangle G_{V}+\frac{k \varepsilon \rho \omega^{2} R^{2}}{2}\right)^{2}\right]
$$

From Eqs. (7) and (9), it is known that the greater the rotation speed $\omega$, that is, the larger the gravity coefficient, the smaller the $\triangle G^{*}$, which is more beneficial to the crystallization of Li metal. Besides, the reduction of $r^{*}$ at a high gravity coefficient means the formation of a small and dense $\mathrm{Li}$ nuclei. As observed in the ether-based electrolyte (Supplementary Figs. 11 and 12), the size of the Li nuclei decreases under supergravity and is inversely proportional to the gravity coefficient. Meanwhile, the density of Li nuclei under the parallel supergravity direction is greater than that of perpendicular supergravity direction, and is more pronounced at high gravity coefficients. Such difference may be attributed to the difference in force and active sites on the electrode surface. In the perpendicular direction, the supergravity can only act on the microscopic protrusions of the electrode surface with a partial supergravity component (Fig. 3b), whereas in the parallel direction supergravity can act anywhere on the electrode surface (Fig. 3c), thus providing a wider range of active sites for Li nucleation.

For the growth stage, under normal gravity condition, the slow mass transfer of $\mathrm{Li}^{+}$cannot quickly compensate for the consumption of $\mathrm{Li}^{+}$, leading to a steeper concentration gradient near the electrode/electrolyte interfaces, which triggers the growth of Li dendrites (Fig. 3d). Conversely, the convection induced by supergravity accelerates ion mass transfer and relaxes the ion concentration gradient on the electrode surface (Supplementary Fig. 13), ultimately promoting the uniform growth of Li metal without a preferential growth direction. Supergravity-induced convection accelerates the ion mass transfer rate, which follows the following double logarithmic relationship ${ }^{36}$.

$$
\log \mu_{0, G}=\log \mu_{0, G=1}+\beta \log G
$$

Where $\mu_{0}$ is ion mass transfer rate, $\beta$ is the Tafel slope. Obviously, supergravity is an important factor to adjust mass transport during metal electrodeposition. Although both gravity directions promote ion mass transfer, compare to the horizontal microconvection induced by perpendicular supergravity direction (Fig. 3e), the longitudinal convection induced by parallel supergravity direction is more beneficial to obtain uniform ion concentration due to the efficient mass transfer behavior (Fig. 3f).

Effect of the supergravity on the electrolyte structure. In addition to the significant changes in the deposition morphology of Li metal, we also found that supergravity has an effect on the SEI composition. Before revealing the characteristics of SEI, it is necessary to understand the changes in the electrolyte at the molecular level under supergravity. Molecular dynamics (MD) simulations were performed to reveal the solvation structure of the electrolyte under supergravity. The simulation system is constructed with $50 \mathrm{LiPF}_{6}, 750 \mathrm{EC}, 400 \mathrm{DEC}$, and $500 \mathrm{EMC}$ molecules, and in a cubic box with a dimension of $6.6 \mathrm{~nm}$ in length $(x)$, width $(y)$, and height $(z)$. Supergravity is equivalent to giving an acceleration to each atom in the system. As shown in the simulation snapshot (Fig. $4 \mathrm{a}, \mathrm{b}), \mathrm{Li}^{+}$associate with $\mathrm{PF}_{6}{ }^{-}$and solvent molecules, leading to certain solvation structures. The structures can be described by the radial distribution function (RDF), which shows how the density of atom $j$ varies as a function of distance from a reference atom $i$ ( $i$ in this case is $\mathrm{Li}^{+}$, and $j$ could be either a solvent molecule or $\left.\mathrm{PF}_{6}{ }^{-}\right)^{37}$.

$$
g_{i r}(r)=\frac{N_{i j}(r) / V(r)}{\rho_{j}}
$$

where $N_{i j}(r)$ is the ensemble averaged number of atoms $j$ in a spherical shell of volume $V(r)$ at a distance $\mathrm{r}$ from atom $i$, and $\rho_{j}$ is the bulk density of atom $j$.

The peak in $g(r)$ for $\mathrm{Li}^{+}$appears at around $0.25,0.29,0.35$, and $0.39 \mathrm{~nm}$ for both $\mathrm{F}$ atoms in $\mathrm{PF}_{6}{ }^{-}$and carbonyl oxygen atoms in EC, DEC, and EMC (Fig. 4c, d), which is consistent with previous reports of $\mathrm{LiPF}_{6}$ in ester electrolyte ${ }^{38}$. This indicates that the $\mathrm{Li}^{+}$ are solvated by solvents and $\mathrm{PF}_{6}{ }^{-}$, forming solvation sheaths around $\mathrm{Li}^{+}$. Meanwhile, supergravity enhances the correlation between $\mathrm{Li}^{+}$and $\mathrm{PF}_{6}{ }^{-}$due to the more pronounced peak intensity. On this basis, the coordination numbers of the $\mathrm{PF}_{6}{ }_{6}$ and solvent molecules surrounding the solvation shell of the ions are calculated from the following integral.

$$
n(R)=4 \pi \rho_{j} \int_{0}^{R} r^{2} g_{i j}(r) \mathrm{d} r
$$

Where $\mathrm{R}$ is the minimum after the first peak in the $\mathrm{RDF} g_{i r}(r)$. As 
a
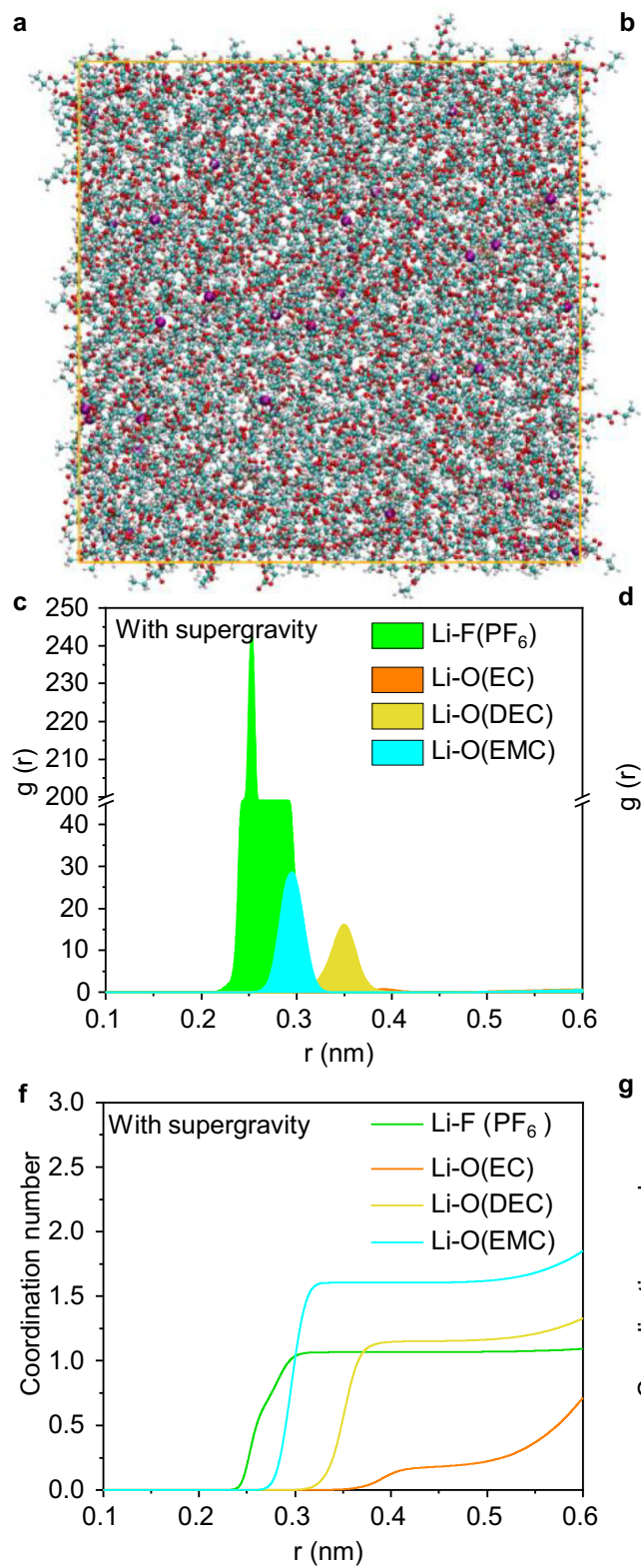

b
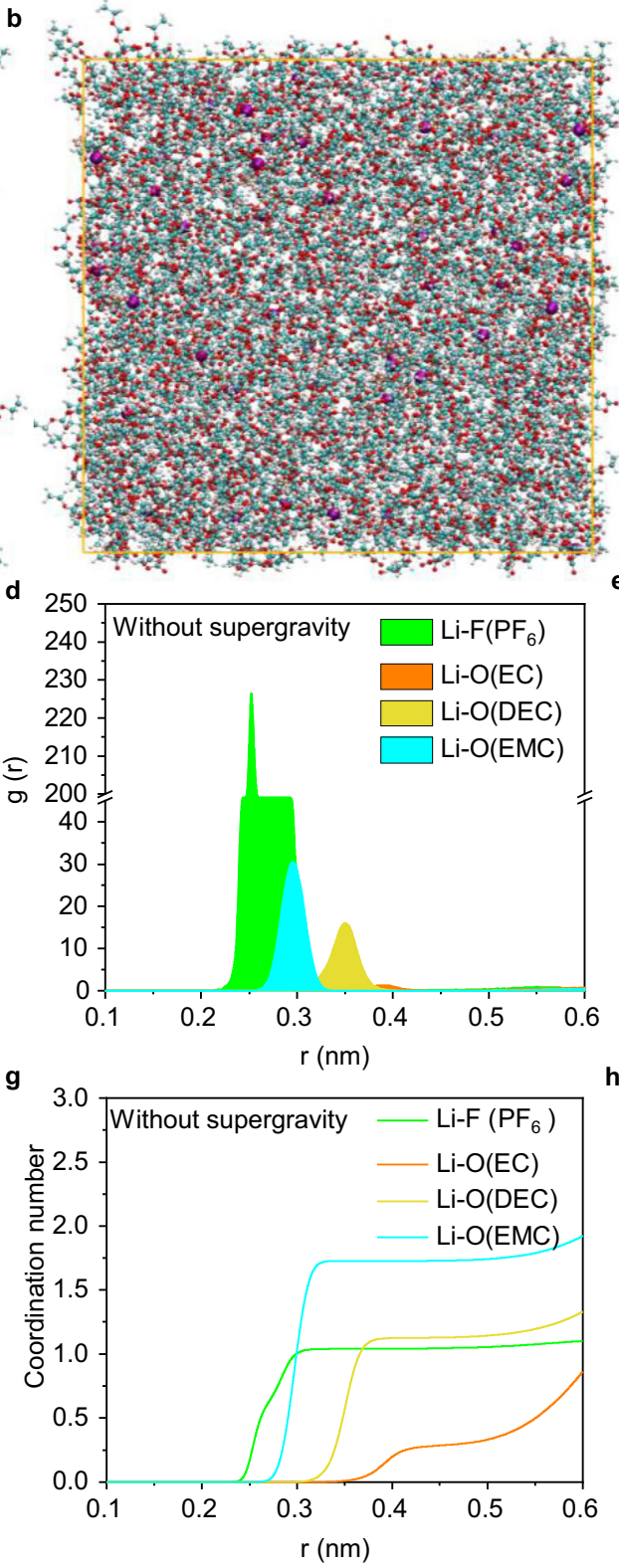

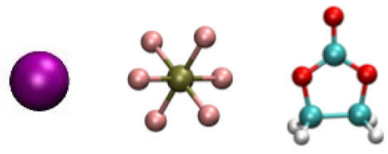

$\mathrm{Li}^{+} \quad \mathrm{PF}_{6}^{-} \quad \mathrm{EC}$
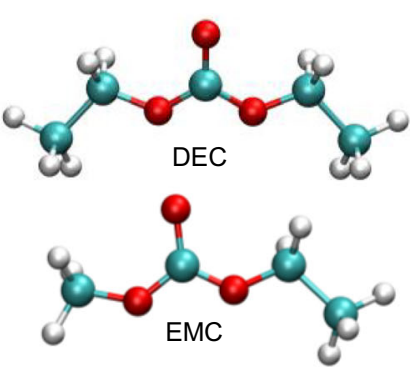

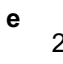



h

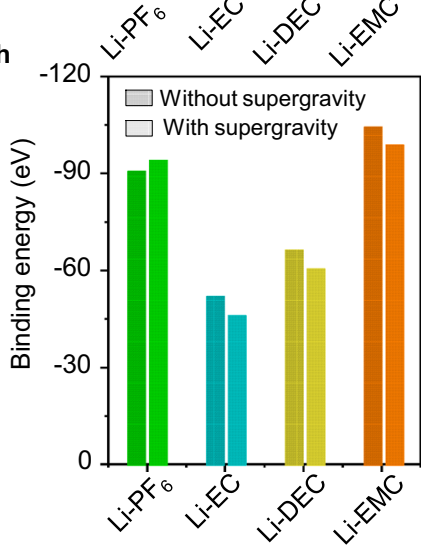

Fig. 4 Solvation structures of the liquid electrolyte solution under different gravity conditions. The snapshot of the MD simulated box a with and

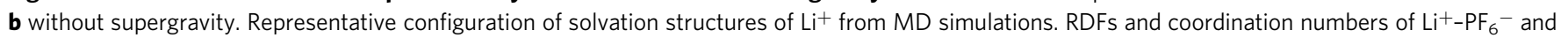

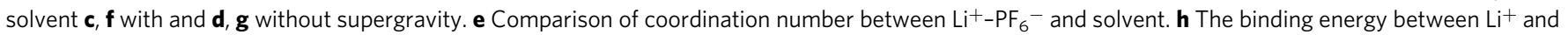
various species calculated by the DFT. Color code: Li+ purple, $\mathrm{P}$ brown, F rose red, $\mathrm{C}$ cyan, $\mathrm{O}$ red, $\mathrm{H}$ white.

shown in Fig. 4e-g, when a supergravity is applied, an apparent trend shows that the coordination number of $\mathrm{PF}_{6}{ }^{-}$with $\mathrm{Li}^{+}$is enlarges from 1.04 to 1.16 while the coordination number of EC, DEC, and EMC reduce from $0.28,1.53$, and 1.71 to $0.18,1.13$, and 1.59 , respectively. The increased anion coordination number strongly implies that $\mathrm{PF}_{6}{ }^{-}$anions are more readily to participate in $\mathrm{Li}^{+}$solvation shell. Density functional theory (DFT) calculations further confirmed this conjecture. The binding energy between $\mathrm{Li}^{+}$and $\mathrm{PF}_{6}{ }^{-}$is increased from -90.23 to $-93.56 \mathrm{eV}$ while weakening the binding energy of other solvent molecules, illustrating a stronger ion association in the electrolyte under supergravity (Fig. 4h).

SEI formation analysis under supergravity. The altering coordination structures greatly determine the preferential decomposition of electrolyte at the anode-electrolyte interface. Quantum chemistry calculations provide a perspective on electrolyte decomposition. Fig. 5a shows the optimized structures of solvents and salt and the corresponding reduction potentials. It can be seen that the reduction potential of $\mathrm{Li}^{+}{ }_{-}$solvent $\left(\mathrm{Li}^{+}-\mathrm{EC}\right.$, $\left.\mathrm{Li}^{+}-\mathrm{DEC}, \mathrm{Li}^{+}-\mathrm{EMC}\right)$ is lower than that of $\mathrm{Li}^{+}-\left(\mathrm{LiPF}_{6}\right)_{2}$, indicating $\mathrm{Li}^{+}-\left(\mathrm{LiPF}_{6}\right)_{2}$ will be reduced first during potential decrease. The enhanced association between $\mathrm{Li}^{+}$and $\mathrm{PF}_{6}^{-}$under supergravity promotes the formation of more $\mathrm{LiF}$ on the surface of Li electrode. As displayed in cyclic voltammetry (CV) curves (Fig. 5b), the sharp $\mathrm{PF}_{6}{ }^{-}$decomposition peak (about $1.6 \mathrm{~V}$ ) is observed in the electrolyte under supergravity, while a relatively weak peak is obtained in the control electrolyte with $1 \mathrm{G}$. Meanwhile, the cathodic peak around $0.6 \mathrm{~V}$ for the electrolytes is attributed to the reduction of the carbonate solvent. Based on these, a schematic illustration is presented in Fig. $5 \mathrm{c}$ to describe 

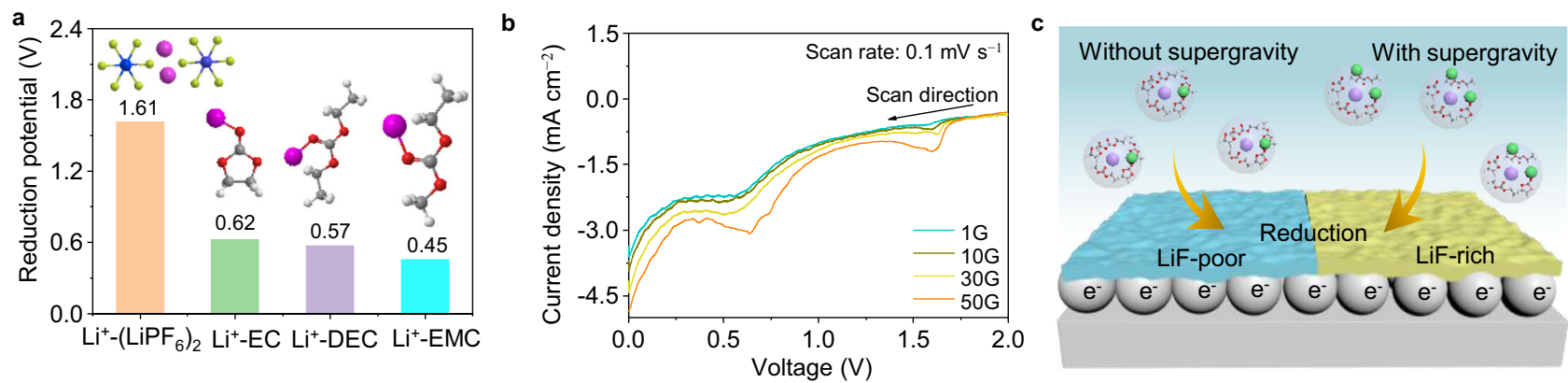

Fig. 5 The formation mechanism of SEI under different gravity conditions. a Reduction potentials of optimized Li+-solvent and $\left(\mathrm{LiPF}_{6}\right)_{2} \mathrm{complexes}$ calculated based on quantum chemistry. b Typical CV curves of Li | |Cu cells under different gravity coefficients. c Schematic illustrations of the SEI formation process. Color code: $\mathrm{Li}^{+}$purple, $\mathrm{PF}_{6}{ }^{-}$green, $\mathrm{F}$ orange, $\mathrm{P}$ blue, $\mathrm{C}$ gray, $\mathrm{O}$ red, $\mathrm{H}$ white.
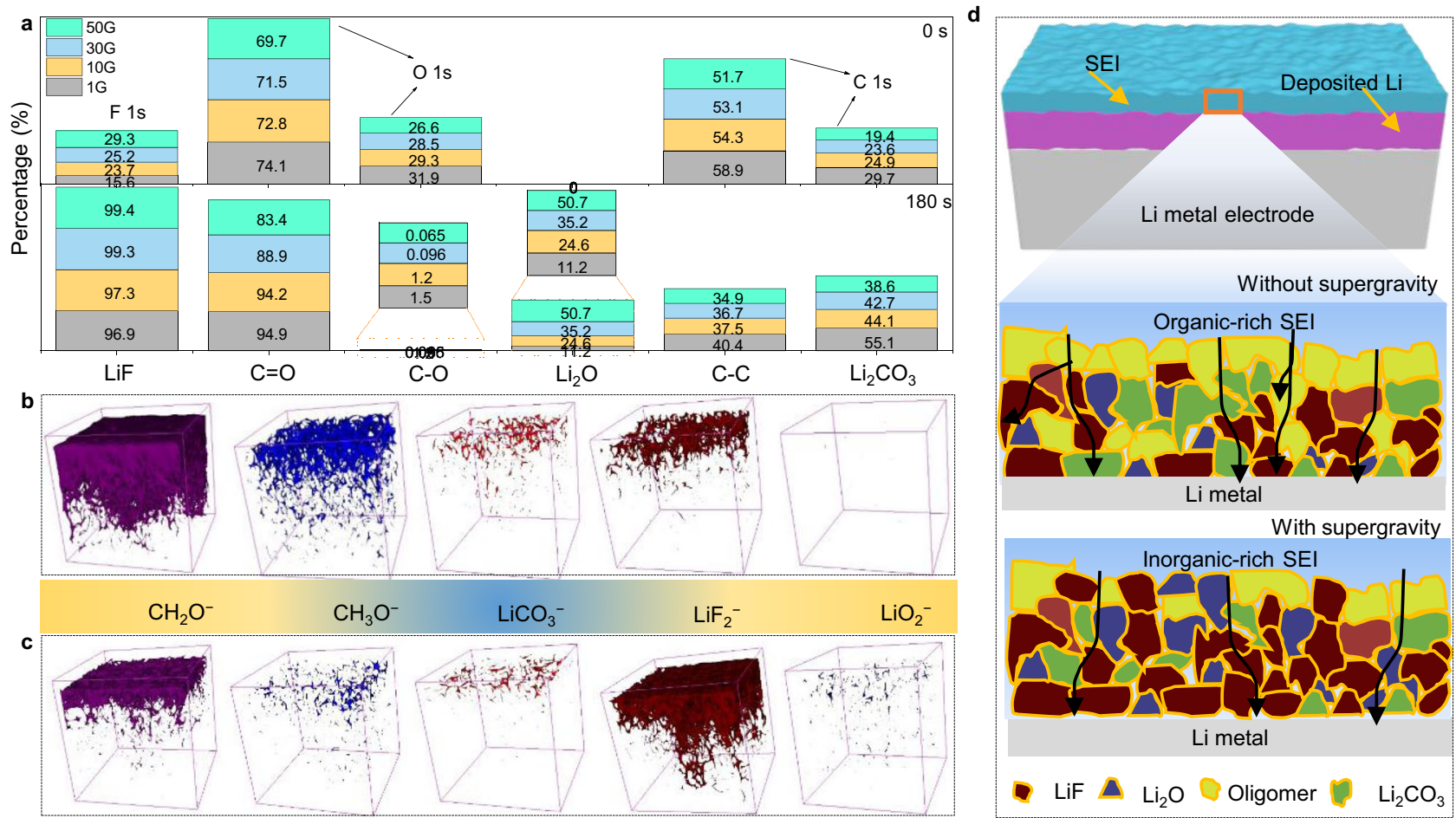

Fig. 6 Characterization of the SEI composition under different gravity conditions. a Comparison of the percentage of each key component in the SEI to the entire spectrum under different gravity coefficients. 3D views of the element distribution in the TOF-SIMS sputtered volumes of cycled Li electrode with gravity coefficient of $\mathbf{b} 1 \mathrm{G}$ and $\mathbf{c} 50 \mathrm{G}$. d Schematic illustration of SEl structure on the surface of Li electrode under normal gravity and supergravity.

the working scenario of the supergravity strategy. Primarily, the Li surface is negatively charged, which is attributed to the spontaneous escape of $\mathrm{Li}^{+}$from the $\mathrm{Li}$ metal surface into the electrolyte. Such negative characteristic leads to the cation enrichment and anion deficiency within the electric double layer due to the electrostatic effect. Therefore, $\mathrm{PF}_{6}{ }^{-}$decomposes less under normal conditions, and the SEI compositions are mainly the decomposition products of organic solvents. However, the inherent interaction between $\mathrm{Li}^{+}$and $\mathrm{PF}_{6}{ }^{-}$can be enhanced under supergravity, leading to more $\mathrm{PF}_{6}{ }^{-}$recruitment into the $\mathrm{Li}^{+}$solvation sheath. These associated solvation clusters are positively charged, allowing more $\mathrm{PF}_{6}{ }^{-}$anion present in an electric double layer, which leads to enhanced decomposition kinetics of $\mathrm{PF}_{6}{ }^{-}$during SEI construction.

SEI composition under supergravity. The distinctive decomposition behaviors of electrolyte under supergravity are bound to affect the composition of SEI. The Li electrodes were collected from the cycled cells under different gravity conditions after 10 plating/stripping for in-depth X-ray photoelectron spectroscopy (XPS) measurements. Fig. 6a compares the percentage of each key component in the SEI to the entire spectrum under different gravity coefficients. The content of LiF increases gradually as the gravity coefficient increases, which is consistent with the intensity of the anion decomposition peak in the CV curves. LiF has been well-known as an SEI component with high interfacial energy and mechanical strength, which can effectively suppress dendrite growth and achieve uniform Li deposition ${ }^{39,40}$. Specifically, the signals of $\mathrm{F} 1 \mathrm{~s}$ spectra for the four SEI films presented peaks corresponding to $\mathrm{LiF}(684.9 \mathrm{eV}), \mathrm{Li}_{x} \mathrm{PF}_{y}(687.1 \mathrm{eV})$, and $\mathrm{Li}_{x} \mathrm{PO}_{y} \mathrm{~F}_{z}$ $(688.9 \mathrm{eV})$, which results from the decomposition of $\mathrm{LiPF}_{6}$ salt (Supplementary Fig. 14a, b) ${ }^{41,42}$. After $180 \mathrm{~s}$ Ar ion sputtering to remove the surface layer, the $\mathrm{LiF}$ peak still exists and the content is higher, indicating its uniform distribution across the depth of SEI. For the O $1 s$ spectrum (Supplementary Fig. 14c, d), a peak at $530.2 \mathrm{eV}$ correspond to $\mathrm{Li}_{2} \mathrm{O}$ and two peaks at 533.1 and $531.3 \mathrm{eV}$ correspond to $\mathrm{C}-\mathrm{O}$ and $\mathrm{C}=\mathrm{O}$, respectively ${ }^{43}$. However, $\mathrm{Li}_{2} \mathrm{O}$ has 
not been detected in the surface of SEI, which only appeared after $180 \mathrm{~s}$ etching, and the peak intensity increases as the gravity coefficient increases. This shows that $\mathrm{Li}_{2} \mathrm{O}$ is not present in the surface layer of SEI, and the application of supergravity helps promote the formation of $\mathrm{Li}_{2} \mathrm{O}$. Note that $\mathrm{Li}_{2} \mathrm{O}$ is an electrically insulating and good ion conductor, which is proven to be beneficial for stabilizing the SEI film ${ }^{44,45} . \mathrm{Li}_{2} \mathrm{O}$ usually comes from the native layer of $\mathrm{Li}$ metal surface and converts from organic species or $\mathrm{Li}_{2} \mathrm{CO}_{3}{ }^{46}$. Besides, the peak intensities of $\mathrm{C}-\mathrm{O}$ and $\mathrm{C}=\mathrm{O}$ become weaker under supergravity, which is attributed to the fact that abundant $\mathrm{LiF}$ and $\mathrm{Li}_{2} \mathrm{O}$ inhibit the parasitic reaction of $\mathrm{Li}$ metal with electrolyte, thereby reducing the decomposition of organic solvents.

For the indicative C $1 s$ spectrum (Supplementary Fig. 14e, f), the organic components derived from the decomposition of solvent molecules, which were deconvoluted into four component peaks, namely $\mathrm{C}-\mathrm{C} / \mathrm{C}-\mathrm{H}(284.7 \mathrm{eV}), \mathrm{C}-\mathrm{O}(286.3 \mathrm{eV}), \mathrm{C}=\mathrm{O}$ $(288.4 \mathrm{eV})$ and $\mathrm{Li}_{2} \mathrm{CO}_{3}(290.1 \mathrm{eV})^{47,48}$. The top surface of the SEI formed at $1 \mathrm{G}$ has a much stronger signal peak, and persists during the subsequent $180 \mathrm{~s}$ sputtering, indicating organic compounds are enriched from the surface to the inner part. Clear organic species are also found under supergravity, but this situation is reversed with the increase of the gravity coefficient. After etching for $180 \mathrm{~s}$, the strength of $\mathrm{C}-\mathrm{C} / \mathrm{C}-\mathrm{H}, \mathrm{C}-\mathrm{O}, \mathrm{C}=\mathrm{O}$, and $\mathrm{Li}_{2} \mathrm{CO}_{3}$ dropped sharply, which indicates that the organic components and $\mathrm{Li}_{2} \mathrm{CO}_{3}$ were mainly distributed in the outer layer of SEI. Abundant inorganic components effectively inhibit the decomposition of the solvent molecules, which is consistent with the performance of organic components in the $\mathrm{O}$ spectrum. $\mathrm{Li}_{2} \mathrm{CO}_{3}$ has a high diffusion barrier and low surface energy for $\mathrm{Li}^{+}$, both of which are undesirable in an SEI film to achieve a dendrite-free morphology ${ }^{49}$. Obviously, the reduction of $\mathrm{Li}_{2} \mathrm{CO}_{3}$ content is more helpful for Li metal batteries to obtain excellent electrochemical performance. In addition, the composition of the electrode surface also changed under perpendicular supergravity direction (Supplementary Fig. 15).

The more detailed composition and structure of the SEI were further characterized by time-of-flight secondary ion mass spectroscopy (TOF-SIMS). Based on the depth profiles (Supplementary Fig. 16) and 3D views (Fig. 6b, c) of several fragments, the interfacial structure and components of the Li metal surface can be clearly revealed. Here, $\mathrm{CH}_{2} \mathrm{O}^{-}, \mathrm{CH}_{3} \mathrm{O}^{-}$represent the organic products of electrolyte decomposition, and $\mathrm{LiCO}_{3}{ }^{-}$, $\mathrm{LiF}_{2}{ }^{-}, \mathrm{LiO}_{2}{ }^{-}$represent the inorganic products of electrolyte decomposition, $\mathrm{Li}_{2} \mathrm{CO}_{3}, \mathrm{LiF}$, and $\mathrm{Li}_{2} \mathrm{O}$, respectively. Compared with $1 \mathrm{G}$, the content of $\mathrm{CH}_{2} \mathrm{O}^{-}, \mathrm{CH}_{3} \mathrm{O}^{-}$, and $\mathrm{LiCO}_{3}^{-}$fragments decreases sharply. The significant contrast mainly stems from the instability of SEI formed at $1 \mathrm{G}$, and the SEI easy to break during charge and discharge, which promotes the parasitic reaction to occur continuously at the rupture of the inner layer of SEI. On the contrary, the content of $\mathrm{LiF}$ and $\mathrm{Li}_{2} \mathrm{O}$ increase under supergravity, which greatly stabilizes the structural integrity, prevents parasitic reactions, and reduces the content of organic components. Meanwhile, the organic components are mainly concentrated in the outer layer, serving as the connectors of SEI to withstand the volume change during cycling. Based on the above analysis, schematic illustrations can be obtained as shown in Fig. $6 \mathrm{~d}$ to depict the distribution features of the components in the SEI. The SEI consists of various components that form a mosaic pattern. For the normal gravity $(1 \mathrm{G})$, organic components run through the entire SEI, and a small amount of $\mathrm{Li}_{2} \mathrm{CO}_{3}, \mathrm{Li}_{2} \mathrm{O}$, and $\mathrm{LiF}$ are randomly embedded here. For supergravity, the SEI mainly consists of stacked inorganic compounds, where inorganic nanocrystallites are dispersed throughout the amorphous matrix. It mainly displays an abundant distribution of inorganic particles, in which $\mathrm{Li}_{2} \mathrm{O}$ and $\mathrm{LiF}$ are more enriched at the metallic $\mathrm{Li}$ interface, and an organic layer on the electrolyte side of the SEI.

The unique structure and composition must endow SEI some peculiar properties. There are more organic components in the SEI on the surface of the Li electrode at $1 \mathrm{G}$, resulting in a low Young's modulus of SEI of only $1.35 \mathrm{GPa}$, which is consistent with reports in the literature $e^{50} . \mathrm{LiF}$ and $\mathrm{Li}_{2} \mathrm{O}$ are typical inorganic components of SEI, with exceedingly high Young's modulus, 64.9 and $169 \mathrm{GPa}$, respectively ${ }^{51}$. Abundant $\mathrm{LiF}$ and $\mathrm{Li}_{2} \mathrm{O}$ can significantly enhance the mechanical strength of SEI and prevent the growth of dendrites. As expected, Young's modulus of SEI shows an escalation tendency when the gravity coefficient is $10 \mathrm{G}$, $30 \mathrm{G}$, and $50 \mathrm{G}$, which are $1.86,2.98$, and $4.21 \mathrm{GPa}$, respectively (Supplementary Fig. 17). The high mechanical strength can inhibit volume expansion and maintain the structural stability of the SEI during the charge and discharge. The interface ion transport behavior of SEI was further evaluated. The SEI resistance $\left(R_{\mathrm{SEI}}\right)$ is significantly decreased under supergravity compared with the normal gravity conditions (Supplementary Fig. 18a and Table 1). The decrease of $\mathrm{R}_{\mathrm{i}}$ is attributed to the increase in the content of $\mathrm{LiF}$ and $\mathrm{Li}_{2} \mathrm{O}$, which can facilitate space charge accumulation, enhance $\mathrm{Li}^{+}$migration, and reduce electron tunneling, thus leading to a high ionic conductivity and a low electronic conductivity of the SEI. Meanwhile, the increased exchange current density also confirms that SEI under supergravity has excellent interfacial ion transport property (Supplementary Fig. 18b). In short, under normal gravity, the SEI with highly resistive organic species is not conducive to $\mathrm{Li}^{+}$diffusion and easily induces charge accumulation, which ultimately aggravates the formation of dendrites. On the contrary, the SEI formed under supergravity is rich in $\mathrm{LiF}$ and $\mathrm{Li}_{2} \mathrm{O}$, which can provide more ion channels to reach the electrode surface uniformly, thus helping to form a uniform morphology.

Practical feasibility assessment of full cells under supergravity. To evaluate the service performance of Li metal batteries under supergravity, $\mathrm{Li}$ foil was paired with a $\mathrm{LiNi}_{0.6} \mathrm{Co}_{0.2} \mathrm{Mn}_{0.2} \mathrm{O}_{2}$-based cathode in a coin cell configuration. Take the supergravity with a gravity coefficient of $50 \mathrm{G}$ as an example for evaluation. Initially, the cell delivered a similar capacity at $1 \mathrm{G}$ and 50G (Supplementary Fig. 19). However, the capacity of the cell decreased steadily from 160 to $101 \mathrm{~mA} \mathrm{~h} \mathrm{~g}^{-1}$ after 200 cycles at $1 \mathrm{G}$, while highly improved capacity retention at $145 \mathrm{~mA} \mathrm{~h} \mathrm{~g}^{-1}$ of the cell for 200 cycles was achieved at 50G. We speculate that the performance difference could be attributed to the stable SEI and uniform Li deposition morphology.

Limited to actual evaluation defects of coin cells, high-energy $\mathrm{Li}$ metal pouch cells were further evaluated under supergravity. In detail, the 2.5 Ah pouch cell with a specific energy of $325 \mathrm{Wh} \mathrm{kg}^{-1}$, obtained by coupling a thin $\mathrm{Li}$ foil and high-loading $\mathrm{LiNi}_{0.8} \mathrm{Mn}_{0.1^{-}}$ $\mathrm{Co}_{0.1} \mathrm{O}_{2}$-based electrode (NCM811, $3.84 \mathrm{~mA} \mathrm{~h} \mathrm{~cm}^{-2}$ ), was designed and fabricated (Supplementary Fig. 20). The specific energy of the assembled pouch cell is calculated by weighing, and the detailed cell parameters are listed in Supplementary Table 2. As expected, the cycle stability of high-energy Li metal pouch cells under supergravity is better than that in normal gravity. Specifically, the former can cycle steadily more than 100 cycles at $1 \mathrm{C}\left(200 \mathrm{~mA} \mathrm{~g}^{-1}\right)$ rate, while the latter can only keep 80 cycles (Supplementary Fig. 21). Even at $2 \mathrm{C}\left(400 \mathrm{~mA} \mathrm{~g}^{-1}\right)$ high rate (Fig. 7a), the pouch cell exhibited capacity retention of $96 \%$ even after 200 cycles at $50 \mathrm{G}$, compared to $84 \%$ after 140 cycles at $1 \mathrm{G}$. The performance at high rates may be related to the plating and stripping mechanism of the Li metal electrode and the prevention of parasitic reactions. Such performance is much competitive comparing with other cell-level 



Cycle number
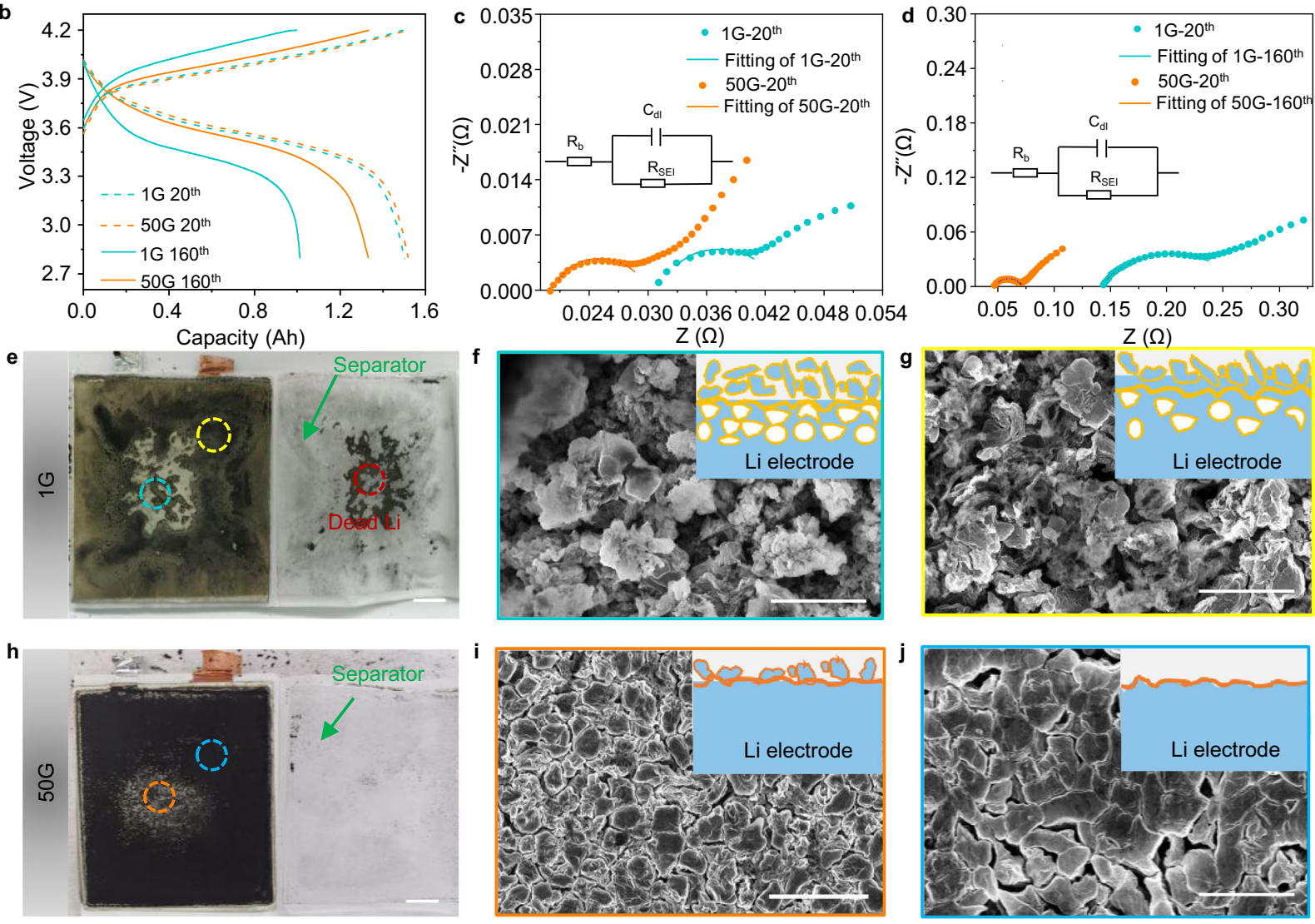

Fig. 7 Electrochemical performances of 2.5 Ah high-energy Li | |NCM811 pouch cell under different gravity conditions. a Cycling performances of pouch cells at 2 C $\left(400 \mathrm{~mA} \mathrm{~g}^{-1}\right)$ rate. b The representative charging/discharging voltage profiles of the pouch cell at $1 \mathrm{G}$ and $50 \mathrm{G}$ with different cycles. Comparison of impedance spectra of pouch cells after c 20 and d 160 cycles at $1 \mathrm{G}$ and $50 \mathrm{G}$ (the inserted equivalent circuit represents the fitted impedance result). e, h Digital photos and $\mathbf{f}-\mathbf{j}$ SEM images of the Li electrode after 160 cycles in pouch cell at $1 \mathrm{G}$ and $50 \mathrm{G}$, respectively (the inserted schematic illustrations show the corresponding electrodeposition morphology). Scale bars are $1 \mathrm{~cm}$ in $(\mathbf{e}, \mathbf{h})$ and $10 \mu \mathrm{m}$ in $(\mathbf{f}, \mathbf{g}, \mathbf{i}$, and $\mathbf{j})$.

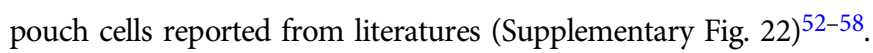
The charging/discharging profiles of the pouch cell further confirm this distinction in performance (Fig. 7b). The cell showed lower capacity attenuation and polarization at $50 \mathrm{G}$ than that at $1 \mathrm{G}$, indicating that the stable SEI and uniform morphology alleviate the parasitic reaction.

Electrochemical impedance spectroscopy (EIS) measurements were carried out to understand the degradation of pouch cells (Fig. 7c, d and Supplementary Table 3). After 20 cycles, the bulk electrolyte $\left(R_{\mathrm{b}}\right)$ and SEI resistance $\left(R_{\mathrm{SEI}}\right)$ of the pouch cell are only 20 and $8 \mathrm{~m} \Omega$ at $50 \mathrm{G}$, while the $R_{\mathrm{b}}$ and $R_{\mathrm{SEI}}$ of the pouch cells are increased to 31 and $11 \mathrm{~m} \Omega$ at $1 \mathrm{G}$. The results showed that the pouch cell forms a stable SEI film with high ionic conductivity during the cycle under supergravity, which can not only inhibit the parasitic reaction but also promote the charge transfer, thus alleviating the increase of $R_{\mathrm{b}}$ and $R_{\mathrm{SEI}}$. Due to the properties of the SEI under supergravity, the values of $R_{\mathrm{b}}$ and $R_{\mathrm{SEI}}$ of pouch cell only increased to 46 and $24 \mathrm{~m} \Omega$ after 160 cycles at $50 \mathrm{G}$. In contrast, $R_{\mathrm{b}}$ and $R_{\mathrm{SEI}}$ of pouch cell increased to 141 and $126 \mathrm{~m} \Omega$, about 3 and 5 times that of the former at $1 \mathrm{G}$. Correspondingly, the escalation of impedance is also associated with the rapid failure of the cycle performance of the pouch cell.

Besides, the disassembled pouch cell provides more insights into the decay mechanism. After 20 cycles (Supplementary Fig. 23), there is no noticeable distinction between the optical morphology of Li metal electrodes at $1 \mathrm{G}$ and $50 \mathrm{G}$ due to the low resolution of the camera, both showing a smooth and dense morphology. Although they also show an approximate morphology under SEM, the surface layer at $1 \mathrm{G}$ is thicker than $50 \mathrm{G}(16 \mu \mathrm{m}$ vs. $9 \mu \mathrm{m})$. After 160 cycles, this diversity is greatly magnified. It was found that the surface of the Li metal electrode became exceedingly rough and incomplete, and some "dead Li" was attached to the separator at $1 \mathrm{G}$ (Fig. 7e). On this basis, two different areas were selected for observation on the electrode 
surface under different gravity conditions. As shown in Fig. 7f, the central area of the electrode presents a porous and loose morphology and contains a large amount of dead $\mathrm{Li}$ at $1 \mathrm{G}$, which is also the reason for the adhesion of dead $\mathrm{Li}$ on the separator. Compared with the central area, the morphology of other areas has been improved to a certain extent, but the poor morphology has not been fundamentally resolved (Fig. 7g). The worse appearance of the central area may be attributed to the uneven pressure applied by the pouch cell during operation. Such poor SEI cannot stabilize the Li metal/liquid electrolyte interface and regulate the electrodeposition behavior of $\mathrm{Li}$ metal, resulting in a torn morphology and a thick cross-section of cycled Li (from 16 to $49 \mu \mathrm{m}$, Supplementary Fig. 24a). In contrast, the Li metal electrode can still maintain its original intact morphology at 50G (Fig. 7h). Meanwhile, the Li growth modulated by supergravity is quite stable as shown from the compact and uniform Li plating in the SEM images of Fig. 7i, j. The homogeneous Li layer with a good contract with Li substrate can be more easily removed during the stripping process as reflected by the small amount of dead $\mathrm{Li}$ or even no dead Li. Meanwhile, the stable SEI also inhibits parasitic reactions between $\mathrm{Li}$ metal and electrolyte under supergravity, resulting in the thickness of the interphase layer only increasing from 9 to $27 \mu \mathrm{m}$ (Supplementary Fig. 24b). Therefore, introducing supergravity not only facilities stable SEI formation and stabilize the Li metal interfacial reactivity, but also regulates electrodeposition behavior of $\mathrm{Li}$ and suppresses dendrite growth, endowing much-improved cycle life in high-energy Li metal pouch cells.

\section{Discussion}

In summary, we creatively considered the gravity factor in the operation of Li metal batteries and revealed the corresponding electrode behavior (deposition morphology, interface properties, and performance) of Li metal. Morphology analysis shows that supergravity can not only inhibit the growth of Li dendrites but also refine Li particles. Moreover, theoretical and experimental results reveal that supergravity enhances the association between $\mathrm{Li}^{+}$and anions, which eventually enables the formation of an anion-derived inorganic-rich SEI. This SEI maintains mechanical stability during cycling and effectively passivates the Li surface, leading to long-term cycling stability. Benefiting from the favorable morphology and SEI, in actual application evaluation, highenergy $\mathrm{Li}|| \mathrm{NCM} 811$ pouch cell $\left(2.5 \mathrm{Ah}, 325 \mathrm{Wh} \mathrm{kg}^{-1}\right)$ can steadily run 200 cycles at $2 \mathrm{C}\left(400 \mathrm{~mA} \mathrm{~g}^{-1}\right)$ rate with a retention rate of $96 \%$. This work lights up blind spots on gravity consideration in battery operation, provides a fundamental insight into the effect of supergravity on battery performance, and broadens the operational environments of batteries. Meanwhile, the effect of microgravity on Li-ion batteries is relatively clear, but remains a mystery for Li metal batteries, and further exploration of the mechanisms involved is necessary due to the unique plating and stripping mechanism of Li metal electrodes.

\section{Methods}

Supergravity experimental equipment. The supergravity is generated by centrifugation derived from a smart agitator. To prevent the power cord from being tangled during the rotation, a conductive slip ring fixed on the ground in the ordinate direction is introduced. The value of gravity coefficient $(G)$ can be adjusted by the speed of the agitator and calculated with the following equation:

$$
G=\frac{L \omega^{2}}{g}=\frac{N^{2} \pi^{2} L}{900 g}
$$

Where $N$ is the rotation speed, $\mathrm{r} \cdot \mathrm{min}^{-1} ; g$ is the gravity acceleration, $9.8 \mathrm{~m} \cdot \mathrm{s}^{-2} ; L$ is the distance from the rotary center to the electrode center.

Physicochemical characterizations. A field emission scanning electron micro scope (SEM, Tecnai G2 F30, FEI, Japan) was employed to obtain deposition morphology under different gravity conditions. X-ray photoelectron spectroscopy (XPS, axis Supra, Kratos, Japan) was performed to characterize the chemical composition of the SEI. Atomic force microscope (AFM, Dimension ICON) was used to analyze the roughness and Young's modulus of the sample surface, and force curves were conducted in the glove box to avoid sample oxidation. AFM tips (BRUKER RTESPA-525) with spring constant of $121 \mathrm{~N} \mathrm{~m}$ ${ }^{-1}$ was used. The value of Young's modulus can be obtained after fitting by Nova-Px-AFM software. The Time-of-flight secondary-ion mass spectroscopy (ION-TOF GmbH, Germany) was applied to observe the distribution of secondary ions on the electrode surface.

Electrochemical measurements. CR2016 coin cells were assembled in an Ar-filled glove box with the content of $\mathrm{H}_{2} \mathrm{O}$ and $\mathrm{O}_{2}$ below $0.01 \mathrm{ppm}$. The Li metal chip (purity 99.95\%, diameter $1.50 \mathrm{~cm}$, thickness $500 \mu \mathrm{m}$ ) as anode, the Celgard 2500 (polypropylene, porosity 55\%, thickness $25 \mu \mathrm{m}$, diameter $1.90 \mathrm{~cm}$ ) as a separator, and $80 \mu \mathrm{L}$ of electrolyte was added to each cell. The $\mathrm{Li}|| \mathrm{Cu}$ cells were assembled to evaluate the deposition morphology and Coulombic efficiency of Li metal electrode under different gravity conditions. The electrolyte was 1.0 M LiTFSI dissolved in 1:1 volume ratio of DME/DOL (moisture content is less than $10 \mathrm{ppm}$ ). The $\mathrm{Li}|| \mathrm{Li}$ symmetric cells were assembled with configurations of Li|electrolyte-separator|Li to evaluate plating/stripping performance, and the electrolyte for each cell was $1.0 \mathrm{M}$ $\mathrm{LiPF}_{6}$ dissolved in 1:1:1 volume ratio of EC/DEC/EMC (Moisture content is less than $10 \mathrm{ppm})$. The $\mathrm{Li}|| \mathrm{NCM} 622$ cells were monitored in galvanization mode within a voltage range of $3.0-4.2 \mathrm{~V}$. Before long-term cycling at the $1 \mathrm{C}\left(180 \mathrm{~mA} \mathrm{~g}^{-1}\right)$, the cells were run at $0.1 \mathrm{C}\left(18 \mathrm{~mA} \mathrm{~g}^{-1}\right)$ for two cycles for better interfacial activation at both anode and cathode. Note that the loading mass of NCM622 is $\sim 13 \mathrm{mg} \mathrm{cm}^{-2}$ (thickness $55 \mu \mathrm{m}$, diameter $1.20 \mathrm{~cm}$ ). $1.0 \mathrm{M} \mathrm{LiPF}_{6}$ in EC/DEC/EMC (1:1:1, by volume) with 5 wt \% fluoroethylene carbonate (FEC) was used as electrolyte (moisture content is less than $10 \mathrm{ppm}$ ).

The assembly of pouch cell was performed with a semi-automated cellmanufacturing line in an Ar-filled glove box with the content of $\mathrm{H}_{2} \mathrm{O}$ and $\mathrm{O}_{2}$ below $0.01 \mathrm{ppm}$, which comprises a Z-stacking machine for the cathode, anode, and separator. The pouch cell uses $50 \mu \mathrm{m} \mathrm{Li}$ (purity 99.95\%) coated on the $\mathrm{Cu}$ foil (thickness $10 \mu \mathrm{m}$ ) as the anode, polyethylene (thickness $9 \mu \mathrm{m}$ ) coated with $\mathrm{Al}_{2} \mathrm{O}_{3}$ (thickness $2 \mu \mathrm{m}$ ) on one side as the separator (porosity $40 \%$ ), high area capacity $\mathrm{LiNi}_{0.8} \mathrm{Co}_{0.1} \mathrm{Mn}_{0.1} \mathrm{O}_{2}$ (NCM811, $3.84 \mathrm{~mA} \mathrm{~h} \mathrm{~cm}{ }^{-2}$ ) as the cathode, and contains an in-house prepared electrolyte (4.5 M LiFSI in DME, the moisture content is less than $10 \mathrm{ppm})$. Note that electrolyte weight to cathode capacity ratio of $2.7 \mathrm{~g} \mathrm{Ah}^{-1}$ Compared with the conventional $1.0 \mathrm{M} \mathrm{LiPF}_{6}$-based electrolyte solutions used in coin cells, the concentrated LiFSI-based electrolyte solution can protect the Li metal electrode and enable the long-term cycling stability of Li metal pouch cells ${ }^{59,60}$. The NCM811 cathode was composed of the active material of $96 \%$, conductive carbon $2 \%$, and binder $2 \%$, and had an area mass loading of about $20 \mathrm{mg} \mathrm{cm}^{-2}$ for a single side. To form a stable SEI, the pouch cells were cycled at $0.1 \mathrm{C}\left(20 \mathrm{~mA} \mathrm{~g}^{-1}\right)$ for two cycles and then stored in a $45^{\circ} \mathrm{C}$ incubator for $12 \mathrm{~h}$. All pouch cells were tested in the voltage range of $2.8-4.2 \mathrm{~V}$ at the rate of $1 \mathrm{C}\left(200 \mathrm{~mA} \mathrm{~g}^{-1}\right)$ or $2 \mathrm{C}\left(400 \mathrm{~mA} \mathrm{~g}^{-1}\right)$ The specific cell parameters for the estimated specific densities are shown in Supplementary Table 2.

All cells (coin cells and pouch cells) were monitored in a LAND multichannel battery cycler (Wuhan LAND Electronics Co., Ltd.) under room temperature $\left(25^{\circ} \mathrm{C}\right)$ without any climatic/environmental chamber. The test of the cell under supergravity or normal gravity is done on the assembled supergravity equipment. In addition, each electrochemical experiment was evaluated 3 times to ensure the validity of the results.

Tafel curves, cyclic voltammetry (CV), and electrochemical impedance spectroscopy (EIS) with different scan rates or voltage ranges were all conducted on a Princeton PARSTAT MC 1000 multi-channel electrochemical workstation. Tafel curves of $\mathrm{Li}|| \mathrm{Li}$ symmetric cells after polarization at $1 \mathrm{mV} \mathrm{s}^{-1}$ from -0.15 to $0.15 \mathrm{~V}$. Typical CV curves of $\mathrm{Li}|| \mathrm{Cu}$ cells scanned between 0 and $2.0 \mathrm{~V}$ at $0.1 \mathrm{mV} \mathrm{s}^{-1}$. EIS measurements were performed on the discharge state after 30 min rest time in the frequency range from $100 \mathrm{kHz}$ to $10 \mathrm{mHz}$ with a perturbation amplitude of $5 \mathrm{mV}$.

Computational details. The classic molecular dynamic (MD) simulations were carried out in this work using the Gromacs-2021.1 software package. A 10 ns NPT relaxation run at $298 \mathrm{~K}$ for the equilibrium MD simulation. The Nose-Hoover thermostat was used to maintain the equilibrium temperature at $298 \mathrm{~K}$ and periodic boundary conditions were imposed on all three dimensions. The Particle Mesh-Ewald method was used to compute long-range electrostatics within a relative tolerance of $1 \times 10^{-6}$. A leap-frog algorithm was used with a time step of $1 \mathrm{fs}$. Supergravity is equivalent to giving an acceleration to each atom in the system. The two systems were simulated for $10 \mathrm{~ns}$, and the data analysis used the $5 \mathrm{~ns}$ after the final balance. Quantum chemistry calculations were performed using a Gaussian 09 software package. The reduction potentials were calculated using the same method as the previous works ${ }^{61}$.

\section{Data availability}

The data that support the findings of this study are available within this article and its Supplementary Information. Source data are provided with this paper. 
Received: 27 July 2021; Accepted: 12 November 2021;

Published online: 10 January 2022

\section{References}

1. Krause, F. C. et al. High specific energy lithium primary batteries as power sources for deep space exploration. J. Electrochem. Soc. 165, A2312-A2320 (2018).

2. Glass, D. E. et al. High temperature primary battery for Venus surface missions. J. Power Sources 449, 227492 (2020).

3. Meng, L. et al. Supergravity separation for recovering metals from waste printed circuit boards. Chem. Eng. J. 326, 540-550 (2017).

4. Brinkert, K. et al. Efficient solar hydrogen generation in microgravity environment. Nat. Commun. 9, 2527 (2018).

5. Gao, Y. et al. Polymer-inorganic solid-electrolyte interphase for stable lithium metal batteries under lean electrolyte conditions. Nat. Mater. 18, 384-389 (2019).

6. Liu, D.-H. et al. Developing high safety Li-metal anodes for future high-energy Li-metal batteries: strategies and perspectives. Chem. Soc. Rev. 49, 5407-5445 (2020).

7. Zou, P. et al. Polymorph evolution mechanisms and regulation strategies of lithium metal anode under multiphysical fields. Chem. Rev. 121, 5986-6056 (2021).

8. Tan, Y.-H., et al. Lithium fluoride in electrolyte for stable and safe lithiummetal batteries. Adv. Mater. 33, 2102134 (2021).

9. Liu, Y.-T., Liu, S., Li, G.-R. \& Gao, X.-P. Strategy of enhancing the volumetric energy density for lithium-sulfur batteries. Adv. Mater. 33, 2003955 (2020).

10. Luo, D. et al. Constructing multifunctional solid electrolyte interface via insitu polymerization for dendrite-free and low N/P ratio lithium metal batteries. Nat. Commun. 12, 186 (2021).

11. Wang, Z. et al. A dendrite-free lithium/carbon nanotube hybrid for lithiummetal batteries. Adv. Mater. 33, e2006702 (2021).

12. Xiao, J. et al. In-situ formed protecting layer from organic/inorganic concrete for dendrite-free lithium metal anodes. Nano Lett. 20, 3911-3917 (2020).

13. $\mathrm{Hu}, \mathrm{Z}$. et al. Dendrite-free lithium plating induced by in situ transferring protection layer from separator. Adv. Funct. Mater. 30, 1907020 (2019).

14. Wang, A., Deng, Q., Deng, L., Guan, X. \& Luo, J. Eliminating tip dendrite growth by Lorentz force for stable lithium metal anodes. Adv. Funct. Mater. 29, 1902630 (2019)

15. Gao, Y. et al. Regulating electrodeposition behavior through enhanced mass transfer for stable lithium metal anodes. J. Energy Chem. 55, 580-587 (2021).

16. O’Neil, W. J. et al. Project Galileo at Jupiter. Acta Astronaut. 40, 477-509 (1997).

17. Bolton, S. J. et al. The Juno mission. Space Sci. Rev. 213, 5-37 (2017).

18. Wei, Y., Yao, Z. \& Wan, W. China's roadmap for planetary exploration. Nat. Astron. 2, 346-348 (2018).

19. Fletcher, L. N. et al. Ice giant system exploration in the 2020s: an introduction. Philos. Trans. A Math. Phys. Eng. Sci. 378, 20190473 (2020).

20. Guo, J., Jiao, W., Qi, G., Yuan, Z. \& Liu, Y. Applications of high-gravity technologies in gas purifications: A review. Chin. J. Chem. Eng. 27, 1361-1373 (2019).

21. Gong, Y., Guo, Z. \& Lu, W. Electroless copper coating on nickel foils in supergravity field. Mater. Lett. 59, 667-670 (2005)

22. Guo, Z., Gong, Y. \& Lu, W. Electrochemical studies of nickel deposition from aqueous solution in super-gravity field. Sci. China Technol. Sc. 50, 39-50 (2007).

23. Eftekhari, A. Enhanced stability and conductivity of polypyrrole film prepared electrochemically in the presence of centrifugal forces. Synth. Met. 142, 305-308 (2004).

24. Liu, T., Guo, Z., Wang, Z. \& Wang, M. Effects of gravity on the electrodeposition and characterization of nickel foils. Int. J. Min. Met. Mater. 18, 59-65 (2011)

25. Wang, M., Wang, Z., Guo, Z. \& Li, Z. The enhanced electrocatalytic activity and stability of NiW films electrodeposited under supergravity field for hydrogen evolution reaction. Int. J. Hydrog. Energy 36, 3305-3312 (2011).

26. Wang, M., Wang, Z. \& Guo, Z. The structure evolution and stability of NiW films electrodeposited under supergravity field. Mater. Lett. 64, 1166-1168 (2010).

27. Mandina, P. et al. Prediction of the electrodeposition process behavior with the gravity or acceleration value at continuous and discrete scale. Electrochim. Acta 53, 233-244 (2007).

28. Cui, Y. et al. An interface-bridged organic-inorganic layer that suppresses dendrite formation and side reactions for ultra-long-life aqueous zinc metal anodes. Angew. Chem. Int. Ed. 59, 16594-16601 (2020).

29. Wang, X., Wang, H., Liu, M. \& Li, W. In-plane lithium growth enabled by artificial nitrate-rich layer: fast deposition kinetics and desolvation/adsorption mechanism. Small 16, 2000769 (2020).
30. Li, Q. et al. Homogeneous interface conductivity for lithium dendrite-free anode. ACS Energy Lett. 3, 2259-2266 (2018).

31. $\mathrm{Li}, \mathrm{Q}$. et al. $\mathrm{Li}^{+}$-desolvation dictating lithium-ion battery's low-temperature performances. ACS Appl. Mater. Inter. 9, 42761-42768 (2017).

32. Kim, Y. K. et al. Implanting a preferential solid electrolyte interphase layer over anode electrode of lithium ion batteries for highly enhanced Li plus diffusion properties. J. Energy Chem. 48, 285-292 (2020).

33. Liu, W., Lin, D., Pei, A. \& Cui, Y. Stabilizing lithium metal anodes by uniform Li-ion flux distribution in nanochannel confinement. J. Am. Chem. Soc. 138, 15443-15450 (2016)

34. Zhao, L., Guo, Z., Wang, Z. \& Wang, M. Influences of super-gravity field on aluminum grain refining. Metall. Mater. Trans. A 41, 670-675 (2010).

35. Gan, Z. et al. Influence of Co contents and super-gravity field on refinement of in-situ ultra-fined fibers in $\mathrm{Al}-2.5 \mathrm{Ni}$ eutectic alloys. J. Alloy. Compd. 822, 153607 (2020).

36. Wang, M., Wang, Z., Gong, X. \& Guo, Z. Progress toward electrochemistry intensified by using supergravity fields. Chemelectrochem 2, 1879-1887 (2015).

37. Li, Q., Tan, S., Li, L., Lu, Y. \& He, Y. Understanding the molecular mechanism of pulse current charging for stable lithium-metal batteries. Sci. Adv. 3, e1701246 (2017).

38. Liu, X. et al. Ethylene carbonate-free propylene carbonate-based electrolytes with excellent electrochemical compatibility for Li-ion batteries through engineering electrolyte solvation structure. Adv. Energy Mater. 11, 2003905 (2021).

39. Cui, C. et al. A highly reversible, dendrite-free lithium metal anode enabled by a lithium-fluoride-enriched interphase. Adv. Mater. 32, e1906427 (2020).

40. Sheng, O. et al. In situ construction of a LiF-enriched interface for stable allsolid-state batteries and its origin revealed by cryo-TEM. Adv. Mater. 32, e2000223 (2020).

41. Hasa, I. et al. Electrochemical reactivity and passivation of silicon thin-film electrodes in organic carbonate electrolytes. ACS Appl. Mater. Inter. 12, 40879-40890 (2020).

42. Langdon, J. \& Manthiram, A. Crossover effects in batteries with high-nickel cathodes and lithium-metal anodes. Adv. Funct. Mater. 31, 2010267 (2021).

43. Laszczynski, N., Solchenbach, S., Gasteiger, H. A. \& Lucht, B. L. Understanding electrolyte decomposition of graphite/NCM811 cells at elevated operating voltage. J. Electrochem. Soc. 166, A1853-A1859 (2019).

44. Guo, R. \& Gallant, B. M. $\mathrm{Li}_{2} \mathrm{O}$ solid electrolyte interphase: probing transport properties at the chemical potential of lithium. Chem. Mater. 32, 5525-5533 (2020).

45. Shen, C. et al. $\mathrm{Li}_{2} \mathrm{O}$-reinforced solid electrolyte interphase on threedimensional sponges for dendrite-free lithium deposition. Front. Chem. 6, 517 (2018).

46. Wu, H., Jia, H., Wang, C., Zhang, J.-G. \& Xu, W. Recent progress in understanding solid electrolyte interphase on lithium metal anodes. Adv. Energy Mater. 11, 2003092 (2020).

47. Liu, S. et al. LiFSI and LiDFBOP dual-salt electrolyte reinforces the solid electrolyte interphase on a lithium metal anode. ACS Appl. Mater. Inter. 12, 33719-33728 (2020)

48. Thanner, K., Varzi, A., Buchholz, D., Sedlmaier, S. J. \& Passerini, S. Artificial solid electrolyte interphases for lithium metal electrodes by wet processing: the role of metal salt concentration and solvent choice. ACS Appl. Mater. Inter. 12, 32851-32862 (2020).

49. Cheng, X.-B., Zhang, R., Zhao, C.-Z. \& Zhang, Q. Toward safe lithium metal anode in rechargeable batteries: a review. Chem. Rev. 117, 10403-10473 (2017).

50. Gu, Y. et al. Designable ultra-smooth ultra-thin solid-electrolyte interphases of three alkali metal anodes. Nat. Commun. 9, 1339 (2018).

51. Wan, G. et al. Suppression of dendritic lithium growth by in situ formation of a chemically stable and mechanically strong solid electrolyte interphase. ACS Appl. Mater. Inter. 10, 593-601 (2018).

52. Liu, W. et al. Artificial solid electrolyte interphase layer for lithium metal anode in high-energy lithium secondary pouch cells. ACS Appl. Energy Mater. 1, 1674-1679 (2018).

53. Zhang, X.-Q. et al. A sustainable solid electrolyte interphase for high-energydensity lithium metal batteries under practical conditions. Angew. Chem. Int. Ed. 59, 3252-3257 (2020).

54. Zhang, K. et al. A high-performance lithium metal battery with ion-selective nanofluidic transport in a conjugated microporous polymer protective layer. Adv. Mater. 33, e2006323 (2021).

55. Li, H. Practical evaluation of Li-ion batteries. Joule 3, 911-914 (2019).

56. Qiao, Y., Deng, H., He, P. \& Zhou, H. A $500 \mathrm{Wh} / \mathrm{kg}$ lithium-metal cell based on anionic redox. Joule 4, 1445-1458 (2020).

57. Niu, C. et al. High-energy lithium metal pouch cells with limited anode swelling and long stable cycles. Nat. Energy 4, 551-559 (2019).

58. Gao, Y. et al. Multifunctional silanization interface for high-energy and lowgassing lithium metal pouch cells. Adv. Energy Mater. 10, 1903362 (2019).

59. Qian, J. et al. High rate and stable cycling of lithium metal anode. Nat. Commun. 6, 6362 (2015). 
60. Wu, S. et al. Hybrid high-concentration electrolyte significantly strengthens the practicability of alkaline aluminum-air battery. Energy Storage Mater. 31, 310-317 (2020).

61. Borodin, O., Olguin, M., Spear, C. E., Leiter, K. W. \& Knap, J. Towards high throughput screening of electrochemical stability of battery electrolytes. Nanotechnology 26, 354003 (2015).

\section{Acknowledgements}

K.X. acknowledges the financial support provided by the National Natural Science Foundation of China (51974256 and 52034011), the Outstanding Young Scholars of Shaanxi (2019JC-12), the Natural Science Basic Research Plan in Shaanxi Province of China (2019JLZ-01 and 2019JLM-29), the Fundamental Research Funds for the Central Universities (3102021ZD0401, 3102021TS0406, 19GH020302, and 3102019JC005), and the Science, Technology, and Innovation Commission of Shenzhen Municipality (JCYJ20180508151856806 and JCYJ20180306171355233). Y.G. acknowledges the Innovation Foundation for Doctor Dissertation of Northwestern Polytechnical University (CX202005). We thank the members from the Analytical \& Testing Center of Northwestern Polytechnical University for the help of SEM and XPS characterization.

\section{Author contributions}

K.X. and Y.G. conceived the experiments and wrote the paper. Y.G. and F.Q. performed major experiments. J.Y., Z.R., N.L., K.Z., C.S., and T.J. provided some electrochemical characterizations. K.X. supervised the research and provided important experimental insights. All authors participated in analyzing the experimental results and preparing the manuscript.

\section{Competing interests}

The authors declare no competing interests.

\section{Additional information}

Supplementary information The online version contains supplementary material available at https://doi.org/10.1038/s41467-021-27429-8.

Correspondence and requests for materials should be addressed to Keyu Xie.

Peer review information Nature Communications thanks Ratnakumar Bugga, and the other, anonymous, reviewer(s) for their contribution to the peer review of this work. Peer reviewer reports are available.

Reprints and permission information is available at http://www.nature.com/reprints

Publisher's note Springer Nature remains neutral with regard to jurisdictional claims in published maps and institutional affiliations.

(c) Open Access This article is licensed under a Creative Commons Attribution 4.0 International License, which permits use, sharing, adaptation, distribution and reproduction in any medium or format, as long as you give appropriate credit to the original author(s) and the source, provide a link to the Creative Commons license, and indicate if changes were made. The images or other third party material in this article are included in the article's Creative Commons license, unless indicated otherwise in a credit line to the material. If material is not included in the article's Creative Commons license and your intended use is not permitted by statutory regulation or exceeds the permitted use, you will need to obtain permission directly from the copyright holder. To view a copy of this license, visit http://creativecommons.org/ licenses/by/4.0/.

(C) The Author(s) 2022 